University of Rhode Island

DigitalCommons@URI

Mechanical, Industrial \& Systems Engineering

Faculty Publications

Mechanical, Industrial \& Systems Engineering

2018

\title{
An Inexpensive Microfluidic PDMS Chip for Visual Detection of Biofilm-forming Bacteria
}

\author{
Rico Kolossa \\ University of Rhode Island \\ Assem Abolmaaty \\ D.M.L. Meyer \\ University of Rhode Island, dmmeyer@uri.edu \\ Zongqin Zhang \\ University of Rhode Island, zhang@uri.edu
}

Follow this and additional works at: https://digitalcommons.uri.edu/mcise_facpubs

Creative Commons License

(c) (1)

This work is licensed under a Creative Commons Attribution 4.0 License.

\section{Citation/Publisher Attribution}

Kolossa, R., Abolmaaty, A., Meyer, D.M.L., \& Zhang, Z. (2018). An Inexpensive Microfluidic PDMS Chip for Visual Detection of Biofilm-forming Bacteria. Annual Research \& Review in Biology, 22(3), 1-13. doi: 10.9734/ARRB/2018/37804

Available at: http://dx.doi.org/10.9734/ARRB/2018/37804

This Article is brought to you for free and open access by the Mechanical, Industrial \& Systems Engineering at DigitalCommons@URI. It has been accepted for inclusion in Mechanical, Industrial \& Systems Engineering Faculty Publications by an authorized administrator of DigitalCommons@URI. For more information, please contact digitalcommons-group@uri.edu. 


\title{
An Inexpensive Microfluidic PDMS Chip for Visual Detection of Biofilm-forming Bacteria
}

\author{
Rico Kolossa ${ }^{1}$, Assem Abolmaaty ${ }^{{ }^{*}}$, D. M. L. Meyer ${ }^{1}$ and Zongqin Zhang ${ }^{1}$ \\ ${ }^{1}$ Department of Mechanical Engineering and Applied Mechanics, University of Rhode Island, \\ Kingston, RI, 02881, USA. \\ ${ }^{2}$ Department of Food Science, Faculty of Agriculture, Ain Shams University, Cairo, Egypt.
}

Authors' contributions

This work was carried out in collaboration between all authors. Authors AA and DMLM designed the study, wrote the protocol, supervised the experimental work and wrote the first draft of the manuscript. Author RK performed the experimental work and statistical analysis. Authors DMLM, AA and ZZ managed the analyses of the study. Authors RK and DMLM managed the literature searches. All authors contributed to manage, edit and approve the final manuscript.

Article Information

DOI: $10.9734 / A R R B / 2018 / 37804$ Editor(s):

(1) Mamdouh Moawad Ali, Professor, Biochemistry Department, Genetic Engineering and Biotechnology Division, National Research Centre, Giza, Egypt. (2) George Perry, Dean and Professor of Biology, University of Texas at San Antonio, USA Reviewers:

(1) Bartosz Kempisty, Poznan University of Medical Sciences, Poland. (2) Michael G. Mauk, Drexel University, College of Engineering, USA. (3) Hongbo Zhang, East China University of Science and Technology, China. (4) Anonymous, University of California, USA (5) Santosh Pandey, lowa State University, USA. Complete Peer review History: http://www.sciencedomain.org/review-history/22694

Original Research Article

Received $17^{\text {th }}$ October 2017

Accepted $7^{\text {th }}$ January 2018 Published 11 ${ }^{\text {th }}$ January 2018

\begin{abstract}
Aims: Design and assembly of an inexpensive microfluidic PDMS chip for visual detection of cell adhesion and biofilm formation.

Study Design: Three different styles of microchannels $(2.6,5.0$, and $11.5 \mu \mathrm{l}$ volumes) were designed, fabricated and tested for adhesion and biofilm formation in a microfluidic system. The pressure drop measurements system includes a bio-Ferrograph connected to the PDMS microchannel via a syringe and a pressure transducer.

Methodology: Microfluidic chips were fabricated using Polydimethylsiloxane (PDMS) by means of soft lithography. Different cell densities of E.coli K12 cells were introduced to investigate adhesion and biofilm formation at different time intervals. Stabilization time and hydraulic resistance were obtained via a Bio-Ferrograph connected to a pressure transducer.
\end{abstract}


Results: PDMS microfluidic volume $(2.6 \mu \mathrm{l})$ failed to generate noticeable biofilm, while slight and greatest yield occurred with PDMS microchannels $(5.0$, and $11.5 \mu \mathrm{l})$, respectively, and could detect as low as 26 cells in $11.5 \mu \mathrm{l}$ microchannel. As incubation time and/or initial cell density increases, cell adhesion increased, illustrated by crystal violet color intensity. High stabilization time $(3 \mathrm{~h})$ didn't allow for bacterial attachment and cultivation inside the microchannel $(2.6 \mu l)$ while lower stabilization time $(10 \mathrm{~min})$ yielded the highest capacity of cell adhesion in microchannel $(11.5 \mu \mathrm{l})$.

Conclusions: We developed a microfluidic chip with low stabilization time and hydraulic resistance, thus offering more volume for adhesion of bacterial cells and biofilm formation. It allowed bacterial cultivation without any addition of nutrients. The microfluidic chip provides a platform to monitor biofilm growth and can be integrated in situ investigations for biological systems, food biotechnology and other industrial biotechnology applications. This would allow a non-destructive and non-invasive monitoring of the biofilm-forming bacteria inside the PDMS microfluidic chip. This work opens opportunities for further investigations of pressure drop phenomena in microchannels that would otherwise go unnoticed in macro scale measurements.

Keywords: Microfluidic; biofilm-forming bacteria; Escherichia coli; PDMS; bio-ferrograph; stabilization time; hydraulic resistance.

\section{INTRODUCTION}

Bacteria can adhere to surfaces by excreting an exopolysaccharide (EPS), which anchors them to all kinds of materials, forming a biofilm [1]. These bacterial biofilms can dramatically affect humans [2]. Centers for Disease Control and Prevention (CDC) estimate that $65 \%$ of human bacterial infections involve biofilms [3]. Poor sanitation of food contact surfaces, equipment, and processing environments have been a contributing factor in food borne disease outbreaks. Foodborne pathogens are associated with biofilms and responsible for many cases of outbreaks, especially those involving Listeria monocytogenes [4,5,6], Salmonella $[7,8]$, and $E$. coli $\mathrm{O} 157: \mathrm{H} 7[9,10]$. Biofilms are not only implied in a significant number of human bacterial infections (food-borne disease and others), they can also be formed inside the body, dramatically increasing the bacterial resistance to antibiotics [11]. Medical implants such as heart valves or artificial joints are significantly affected by biofilms. These device-related infections are very difficult to clean because of the protection that biofilms offer the bacteria [12]. Improperly cleaned conduits in food processing, pharmaceutical industry, and medical devices may promote dirt buildup. In the presence of water, this contributes to the development of bacterial biofilms, which may contain pathogenic microorganisms. Biofilms can also increase the corrosion in the inner surface, reduce the heat flow across the devices, or increase the fluid frictional resistance at the surface [13]. Here the biofilms can greatly reduce the operating efficiency and thus result in decreased productivity as well as downtime and replacement costs [14]. Dental Plaque is a good example to show that biofilms are not merely some cells in a sticky matrix. There are more than 300 different bacterial species living in a microbial community around a tooth [2]. Biofilmformation is influenced by cell surface properties including the presence of capsules, fimbriae, and cell surface hydrophobicity [14], which are based on compounds associated with the outer membrane, including lipopolysaccharides, lipoproteins, lipoteichoic acid, and lipomannan. Some bacteria can also excrete substances before or after attachment, which increases hydrophobicity of the cell surfaces [15]. Direct detection and monitoring of pathogen-containing biofilms play a major role in controlling the spread of foodborne disease [16]. Numerous methods such as direct microscopic enumeration, total viable count, metabolically active dyes, radiochemistry, and fluorescence, have been used to investigate microbial biofilms $[17,18]$. Many of them require invasive sampling and removal of biofilm material from a surface because of its total biomass, microbial composition, and biological interaction with surfaces. The amount of biofilm that has to be removed is often limited by the size of the laboratory biofilm reactors. Therefore, nondestructive and non-invasive detection techniques to monitor biofilm accumulation and activity are of major interest. Several approaches have been developed to increase the reproducibility of biofilms and to cultivate biofilms under conditions of fluid flow [19]. Microfluidic systems are becoming more important in modern life sciences, diagnostics and therapeutics, and in biomedical engineering [20]. Another device employs hydrodynamic effects inside the 
microchannel to encapsulate and sort cells [21]. Cell encapsulation allows for observation and analysis of individual cells (e. $\mathrm{g}$ with drugs or reagents) in an automated and swift manner. Recent trends in cell biology emphasize singlecell studies in micro technologies raising the hope for dramatic breakthroughs in this field [22]. Microfluidic devices are continuously being developed for many different applications: Clinical, DNA, and proteomics analyses, immunoassays, toxicity monitoring, and even forensic analysis [23]. The routine assay of many biofilm forming bacterial isolated from clinical specimens and foods frequently involves the use of microliter plates. In considering the cost of commercially available plates, we undertook to significantly reduce the cost of each assay by developing a microfluidic biofilm assay. Our previous work indicated that the hydrophobic characteristic of the PDMS internal surfaces allowed the adsorption of hydrophobic targets such as bacterial cells [24] and uniformity distribute them along the larger surface area of PDMS mini channels $(200 \mu \mathrm{l})$. Biofilm formation of Listeria monocytogenes, Salmonella enteritis, and $E$. coli O157:H7 in PDMS channel was apparently higher than microliter plates when nutrients in their surroundings became limited [24]. A PDMS flow cell was later developed for quantitative monitoring and studying biofilm stages of $E$. coli $0157: \mathrm{H} 7$ in the beverage industry [25]. The novelties of this work lie within the design and assembly of different styles of PDMS microfluidic chips for studying the adhesion and biofilm formation inside microchannels using $E$. coli $\mathrm{K} 12$ as a nonpathogenic model for pathogenic bacteria. The microfluidic chip provides a platform to monitor biofilm growth. Based on our knowledge, this microfluidic chip is the smallest chip to investigate different steps in biofilm formation. Different design and styles can be customized and integrated for in situ investigation of initiating the adhesion and biofilm formation for biological systems, food biotechnology and other industrial biotechnology applications. This would allow the continual replacement of fresh nutrients, in a similar manner as in the real environment, whether medical, food beverage, natural or industrial. This work opens opportunities for further investigations of pressure drop phenomena in microchannels that would otherwise go unnoticed in macro scale measurements. This would allow a nondestructive and non-invasive monitoring of the biofilm-forming bacteria inside the PDMS microfluidic chip.

\section{MATERIALS AND METHODS}

\subsection{Fabrication of PDMS Microfluidic Chip}

A photomask (Fig. 1) was designed using a computer-aided design (CAD) program Art Services, Inc (Bandon, OR). The microchannels were fabricated from Polydimethylsiloxane (PDMS) by means of soft lithography, the most successful technology in microfabrication [26,27]. Three different designs of PDMS microfluidic chips were fabricated with different masked photoresist and channel volumes $(2.6 \mu \mathrm{l}, 5.08 \mu \mathrm{l}$, and $11.5 \mu \mathrm{l})$. To fabricate the microchannels, SU82100 photoresist (Microchem, Newton, MA) was coated on a 4-inch silicon wafer. The masked photoresist was then patterned by exposing it to 365-nm collimated light, followed by post baking at $95^{\circ} \mathrm{C}$ for 30 minutes. It was then developed in SU-8 developer (Microchem, Newton, MA) and rinsed in SU-8 developer (Microchem) to form the SU-8 structure. Liquid PDMS was prepared by mixing PDMS base with a curing agent at a ratio of 10:1. The mixture was degassed and then poured onto the mold. After 45 minutes of hardening at $90^{\circ} \mathrm{C}$, elastomeric PDMS was peeled from the wafer and holes were punched through at the ends of the microchannels to assist with lining up the microchannel layers during assembly. The incubation reservoir was built by joining two layers of PDMS. The peeled PDMS was then bonded to a flat PDMS pad by plasma treatment in an oxygen environment, forming closed volumes of microchannels. Fig. 1 presents the photomasks and the micrograph of these microchannels.

\subsection{Microorganism Cultivation}

E. coli K12 strain MG1655, obtained as a gift from the department of Cell and Molecular biology, University of Rhode Island), was routinely grown in $50 \mathrm{ml}$ of Tryptic Soy Broth (Difco, Detroit, MI)) plus $0.5 \%$ glucose $\left(\mathrm{TSB}^{+}\right.$) at $37^{\circ} \mathrm{C}$ in $250 \mathrm{ml}$ baffled flasks with rotary agitation $(200 \mathrm{rpm})$. Exponentially growing cells $\left(\sim 1 \times 10^{9}\right.$ cells $/ \mathrm{ml}$ ) were harvested by centrifuging broth cultures at $13000 \mathrm{~g}$ for $10 \mathrm{~min}$ at $4^{\circ} \mathrm{C}$. Pellets were re-suspended in sterile saline solution, pelleted again and the concentration of cells adjusted as required by re-suspending in either saline or $\mathrm{TSB}^{+}$as needed. Cell densities were determined using plate counts with Tryptic Soy Agar (TSA) and the corresponding absorbance at $600 \mathrm{~nm}$ using a Biophotometer 
Eppendorf AG (Hamburg, Grermany) spectrophotometer.

\subsection{The Effect of Initial Cell Density on Biofilm Formation}

This study was conducted for the three designs of PDMS as mentioned above (Fig. 1). PDMS chips were rinsed with $95 \%$ ethanol three times using a syringe with a tube connected to the channel inlets (Fig. 2) and then aseptically air dried at $37^{\circ} \mathrm{C}$ until used. To study the effect of initial cell adhesion on biofilm formation, TSB+ media containing different concentrations of $E$. coli K12 $\left(2 \times 10^{3}, 2 \times 10^{4}, 2 \times 10^{5}, 2 \times 10^{6}\right.$, and $2 \times$ $10^{7}$ cells / ml, unless otherwise stated), were aseptically added into the PDMS chips and incubated at $37^{\circ} \mathrm{C}$ for $12 \mathrm{~h}$. PDMS chips were emptied from the broth media and then subjected to another $24 \mathrm{~h}$ of incubation at $37^{\circ} \mathrm{C}$ for biofilm formation. To ensure that the contents of the PDMS channels did not dry up during the biofilm formation, each were placed in the upper shelf of plastic boxes (Fig. 2), designed for $1.0 \mathrm{ml}$ automatic pipette tips, that were partly filled with $5 \mathrm{ml}$ distilled water. After the incubation period was complete, the microchannels were washed with sterile distilled water to remove all planktonic bacteria and then washed three times with sterile distilled water to remove loosely associated bacteria. Subsequently, Crystal Violet (CV) was introduced into the microchannels and incubated inside the microchannels for $45 \mathrm{~min}$ at room temperature. CV was then washed out with distilled water. At this point, stained biofilms were visible as purple layers formed on the sides of each channel. To improve the visibility of $\mathrm{CV}$, ethanol was added to the channels. The introduced ethanol volume must be the exact volume of the microchannel. To avoid evaporation of the ethanol, the microchannels were sealed with a PDMS plug. The plug was fabricated by using the same biopsy punch that was used to punch the inlet and outlet. The PDMS biofilm assay was performed at least in triplicate. Images were taken for both stained and de-stained biofilm using a digital camera. Stained images were obtained after the removal of $\mathrm{CV}$ as an indicator of successful biofilm formation on the inner wall of PDMS microchannels. However, de-staining with ethanol increases color intensity for inexpensive assay of clear visual observation.
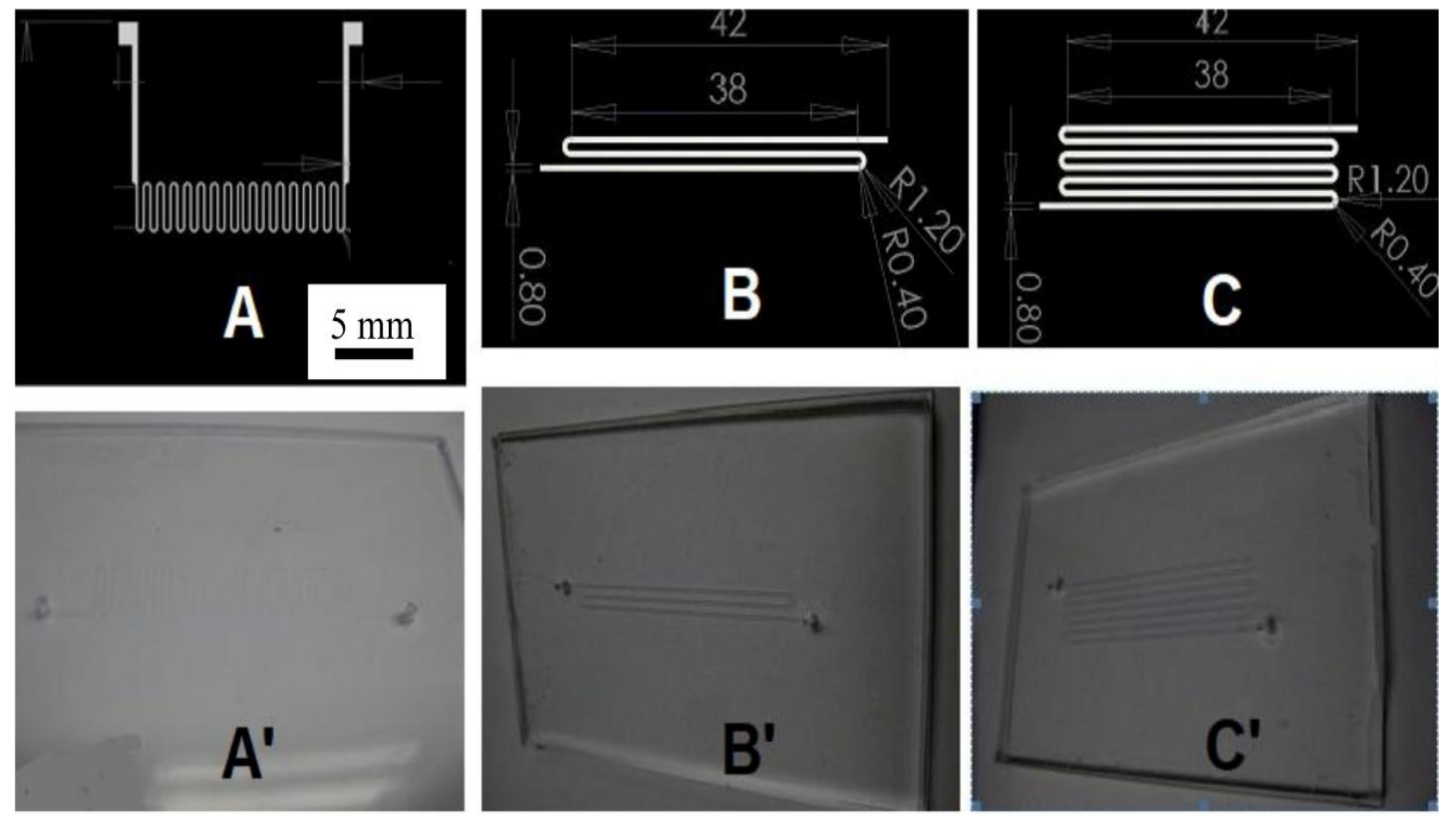

Fig. 1. Different design and fabrication of PDMS microfluidic chips

The microchannel was fabricated from PDMS by means of soft lithography. Three different designs of PDMS microfluidic chips were fabricated with different channel volumes, $A^{\prime}(2.6 \mu \mathrm{l}), B^{\prime}(5.08 \mu \mathrm{l})$, and $C^{\prime}(11.5 \mu \mathrm{l})$ using different masked photoresists $(A, B$, and $C)$ respectively. Channel cross-sectional dimensions are $50 \mu m$ high $x$ $400 \mu \mathrm{m}$ wide with varying lengths 

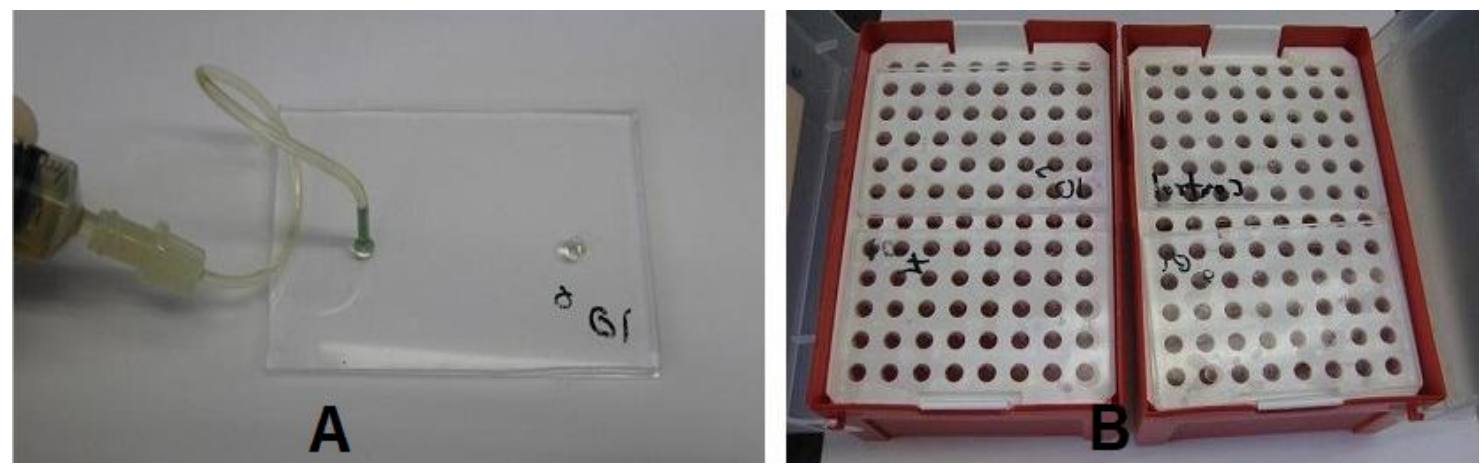

Fig. 2. Microfluidic chip system

Experimental set up showing a syringe connected to the channel inlet (A) and plastic boxes (B) used for biofilm formation

\subsection{The Effect of Incubation Time on Cell Adhesion}

To study the effect of incubation time on biofilm formation, a cell suspension of $1 \times 10^{5} \mathrm{E}$. coli K12 in $\mathrm{TSB}^{+}$was delivered to PDMS channels $\left(\mathbf{C}^{\prime}\right.$ $11.5 \mu \mathrm{l})$ using a syringe tube and incubated at $37^{\circ} \mathrm{C}$ for different time intervals $(0,3,6,9$, and $12 \mathrm{~h})$. The planktonic culture media was gently removed after cell adhesion periods were completed. After another 24 hours of incubation, channels were washed three times with sterile saline to remove loosely associated bacteria. Control was conducted by adding sterile $\mathrm{TSB}^{+}$to the control channels. Crystal Violet $(1.0 \%$ in water) was introduced to the channels and incubated at room temperature for $45 \mathrm{~min}$ followed by washing the channels with sterile distilled water three times. The PDMS biofilm assay was performed at least in triplicate. Images were taken using a digital camera.

\subsection{Pressure Drop Measurements}

Pressure drop measurements were conducted to ensure that the designed microchannels and the setup of the experiment were compatible. PDMS microfluidic chips of each design (A' $5.0 \mu \mathrm{l}$, B' $11.05 \mu \mathrm{l}$ and $\mathbf{C}^{\prime} 2.6 \mu \mathrm{l}$ ) were subjected to different concentrations of $E$. coli K12 (3.55 x $10^{3}, 3.55 \times 10^{5}, 3.55 \times 10^{6}, 3.55 \times 10^{7}$ cells $\left./ \mathrm{ml}\right)$ prepared in TSB+ and incubated for $12 \mathrm{~h}$ as described above. After cell adhesion periods were complete, the planktonic culture media was gently removed and then subjected to another 24 hours for biofilm formation. Sterile saline was then introduced to the channels via the BioFerrograph at the same constant volumetric flow rate of $0.1 \mathrm{ml} / \mathrm{min}$ to ensure uniformity. Since each cross-sectional area of the microchannels differs, the velocity of the sterile saline wash in each channel will also be different. Hence, using the same constant volumetric flowrate over the varying cross-sectional areas ensures the wash is delivered uniformly. In this manner, differences in pressure drop readings if any, are emphasized. Stabilization time and hydraulic resistance were obtained via the Bo-Ferrograph connected to a pressure transducer (Fig. 3). The theoretical values of hydraulic resistance $R_{\text {hydr }}$ are calculated using [28],

$$
R_{h y d r}=\frac{128 \eta l_{c}}{\pi D_{H}{ }^{4}}
$$

and are found in Table 1. Here, $I_{c}$ is the length of the microchannel, $\eta$ is the absolute viscosity of water, $D_{H}$ is the hydraulic diameter, defined as $\frac{2(h \cdot w)}{h+w}$ for rectangular microchannels, where $\mathrm{h}$ is the height and $w$ is the width of the channel, respectively. Since $R_{\text {hydr }}$ is inversely proportionate to the $D_{H}$ to the fourth power, it demonstrates that very small changes in $D_{H}$ results in significant changes in $R_{\text {hydr }}$. The theoretical values of pressure drop $\Delta \mathrm{p}$, also tabulated in Table 1, are calculated as,

$$
\Delta p=R_{h y d r} \cdot Q
$$

where $Q$ is the volumetric flowrate. The experimental pressure drop data obtained from the pressure transducer was collected by connecting to a computer. Control measurements were taken for each channel before adding bacterial cells. 


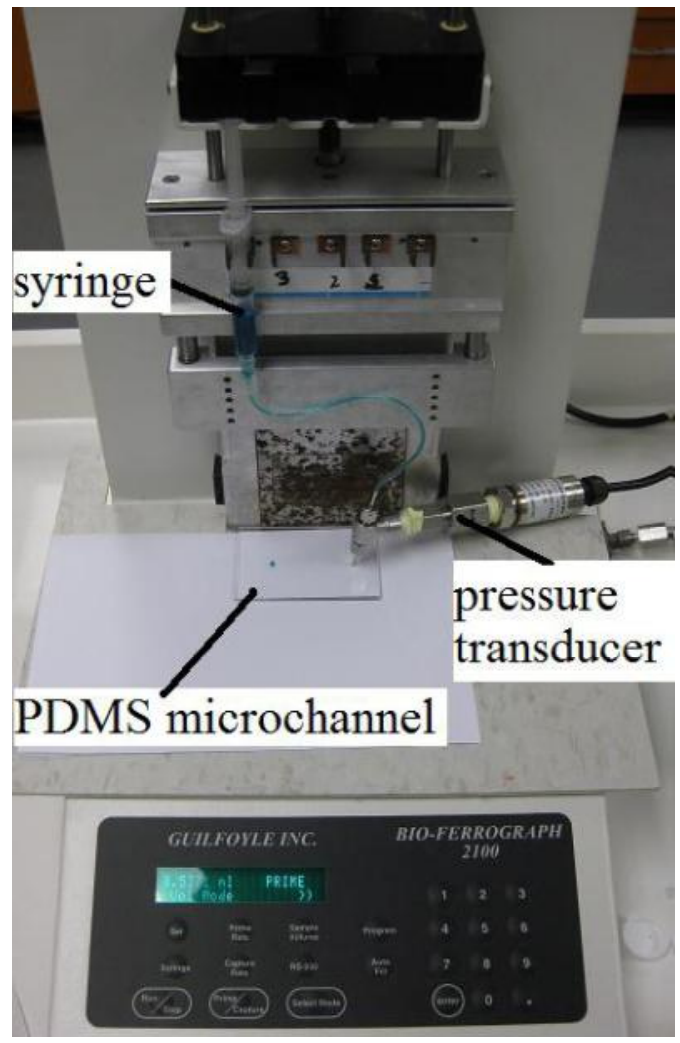

Fig. 3. The pressure drop measurement setup

A Bio-Ferrograph is connected to the PDMS microchannel via a syringe where a pressure transducer is installed within the system. This leads the fluid through a tube with a pressure transducer connected to the microchannel

\section{RESULTS AND DISCUSSION}

\subsection{The Effect of Initial Cell Density and Biofilm Formation}

Nowadays, nanotechnology and microfluidics have emerged in science and technology. The proof of concept was previously achieved and published [24,25] with mini channels $(200 \mu \mathrm{l})$. However, these channels do not mimic tiny tubes in biological systems and/or in industrial biotechnology applications. This study was conducted with different numbers of bacteria (2.3 $\times 10^{3}, 2.3 \times 10^{4}, 2.3 \times 10^{5}, 2.3 \times 10^{6}, 2.3 \times 10^{7}$ cells $/ \mathrm{ml}$ ), unless otherwise stated. Three designs of microfluidic PDMS channels were used in this study. The first attempt to design and fabricate a microchannel volume (A': $2.6 \mu \mathrm{l})$ did not allow biofilm to grow (Fig. 4). Microchannel diameters were very small and did not allow enough oxygen for biofilm growth. Nutrient availability also has a different impact on bacteria of various species. Biofilm formation of $E$. coli were found to be repressed by the presence of glucose [27]. Yet enteroaggregative $E$. coli's (a certain pathogenic E. coli strain) tendency to form biofilm is promoted by the abundance of glucose [27]. The lack of oxygen has also a negative impact on the initial adhesion of $E$. coli $K 12$ [28]. For these reasons, different photomask designs were developed with larger channel volumes. The small channel (B': $5.0 \mu \mathrm{l}$ ) improved the color intensity of stained and de-stained biofilm formation (Fig. 5) while the larger channel volume (C': $11.5 \mu \mathrm{l})$ generated the greatest yield of biofilm (Fig. 6). Since the channel volume is larger, it can hold enough oxygen and enough traces of nutrient for biofilm formation. Moreover, it does not become dry easily. This microfluidic chip successfully produced biofilm from an initial cell density of $2.3 \times 10^{3}$ cells $/ \mathrm{ml}$ ( 26 cells / channel). The three different designs microfluidic PDMS channels showed great impact on cell adhesion and biofilm formation. This phenomenon was repeatedly observed several times throughout the whole study with three different designs of microfluidic PDMS channels (Figs. 4, 5, 6). Various cell densities of $\mathrm{K} 12$ incubated at $37^{\circ} \mathrm{C}$ for $12 \mathrm{~h}$ in PDMS microchannels showed slight impact on cell adhesion and biofilm formation. Digital images have indicated that the channel volume of $11.5 \mu \mathrm{l}$ can be used to detect both staining and destaining biofilm (Fig. 6).

\subsection{Effect of Incubation Time on Adhesion of Bacterial Cells and Biofilm Formation}

When the PDMS channels $(11.5 \mu \mathrm{l})$ were subjected to the broth culture media containing 1 $\times 10^{5} \mathrm{cells} / \mathrm{ml}$ ( 1150 cells/ channel) of $E$. coli $\mathrm{K} 12$ at different time intervals $(3,6,9$, and $12 \mathrm{~h})$, emptied and then incubated for another $24 \mathrm{~h}$, the digital images of CV staining biofilm was visually observed as a purple color inside the channels (Fig. 7).

It is of interest to mention that the use of the microfluidic chip (C': $11.5 \mu \mathrm{l}$ ) allowed bacteria to adhere to the inner surface and excrete an exopolysaccharide (EPS), or glue-like substance that can anchor them to PDMS inner surfaces after 3 hours of incubation. It also allowed for biofilm formation without filling the microchannels with any nutrient media. Attached microorganisms just used traces, left over from after wash of planktonic media, and successfully 
grew at different incubation time intervals (Figs. $6,7)$. An increase in the color intensity of biofilm formation occurred with the increase of incubation periods (Fig. 7) at $37^{\circ} \mathrm{C}$ as oxygen becomes more available for biofilm formation in
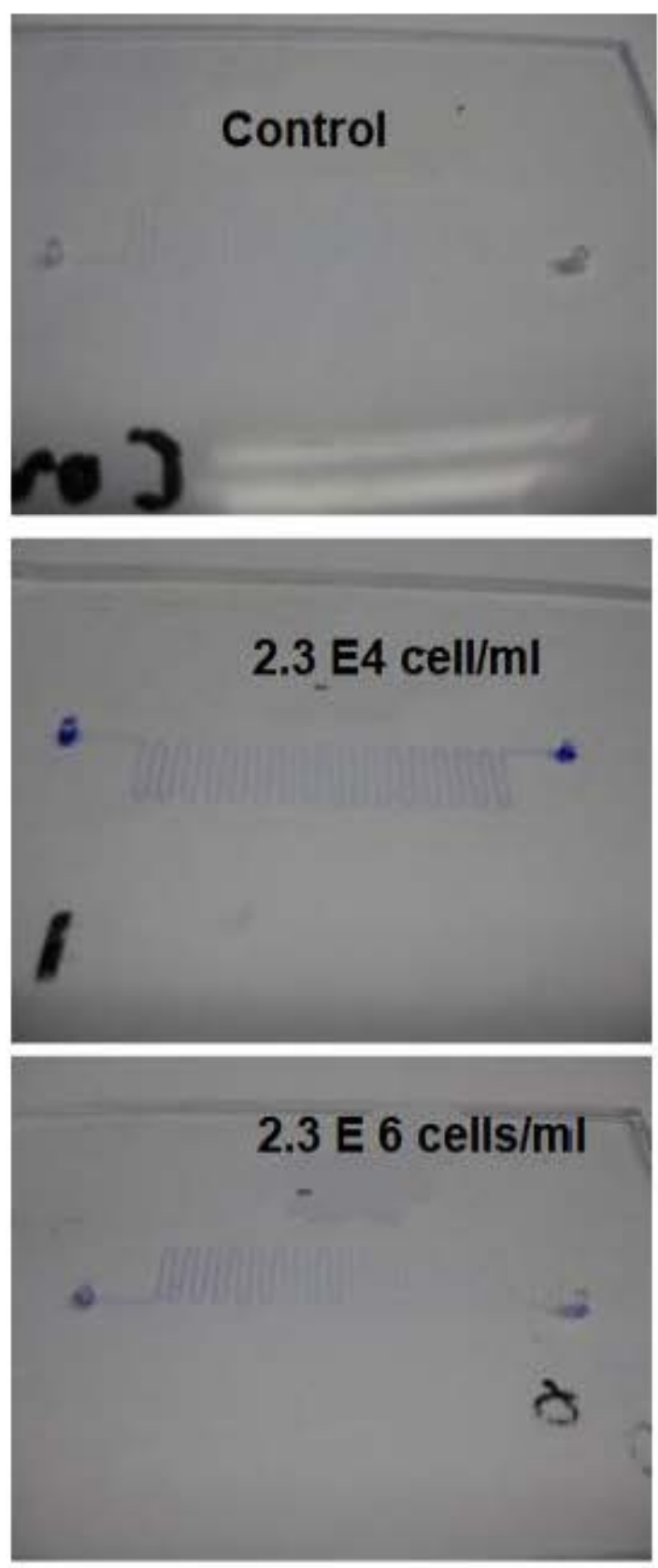

the microenvironment. The maximum yield of the biofilm was obtained after $12 \mathrm{~h}$ of incubation. Undoubtedly, various incubation times have significant impact on color intensity of biofilm formation.
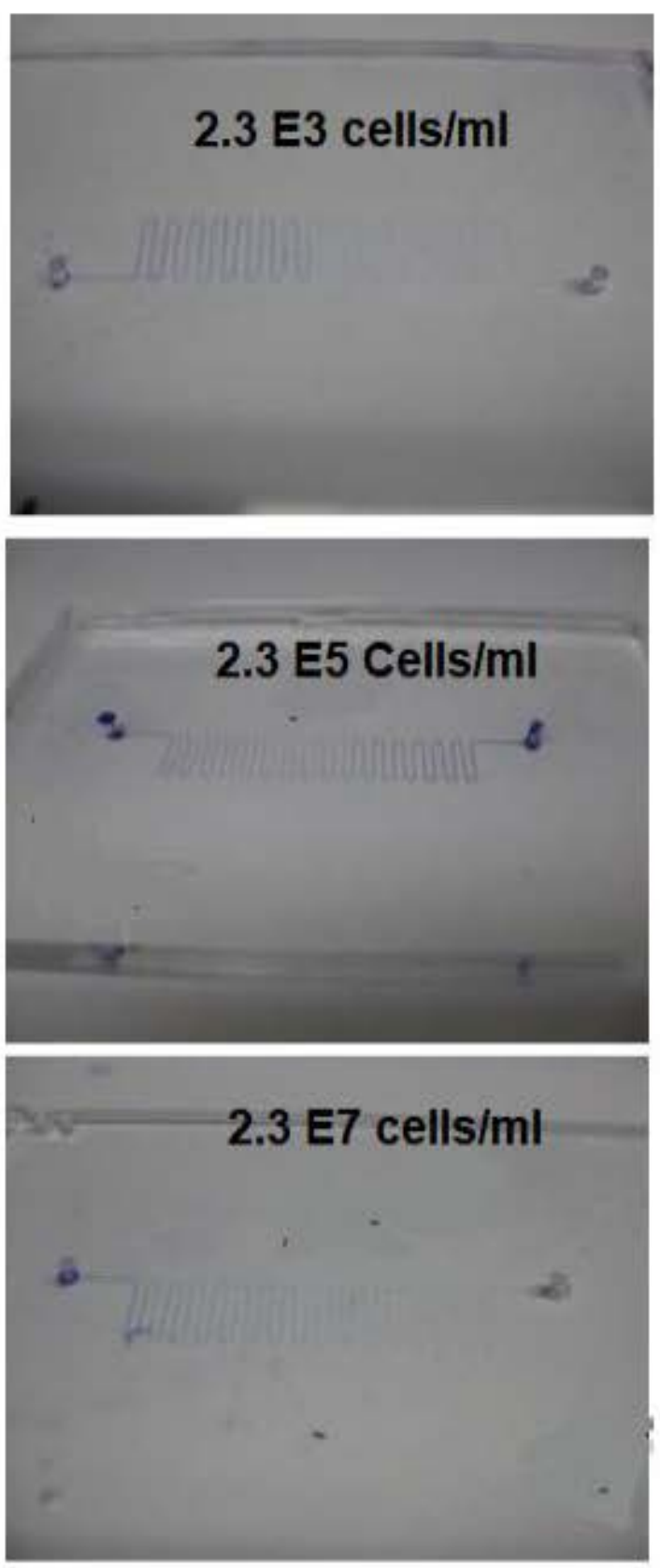

Fig. 4. PDMS microfluidic chip $(2.6 \mu \mathrm{l})$ tested for biofilm formation

Different numbers of bacteria $\left(2.3 \times 10^{3}, 2.3 \times 10^{4}, 2.3 \times 10^{5}, 2.3 \times 10^{6}, 2.3 \times 10^{7}\right.$ cells $\left./ \mathrm{ml}\right)$ were introduced to the microchannels and incubated at $37^{\circ} \mathrm{C}$ for $12 \mathrm{~h}$. PDMS chips were emptied of the planktonic media, subjected to another $24 \mathrm{~h}$ of incubation and then washed three times with sterile saline. Controls were conducted by adding sterile $T S B^{+}$to the control channels. Crystal Violet was introduced at room temperature for 45 min followed by washing with sterile distilled water three times. Images of de-staining chips were taken using a digital camera 

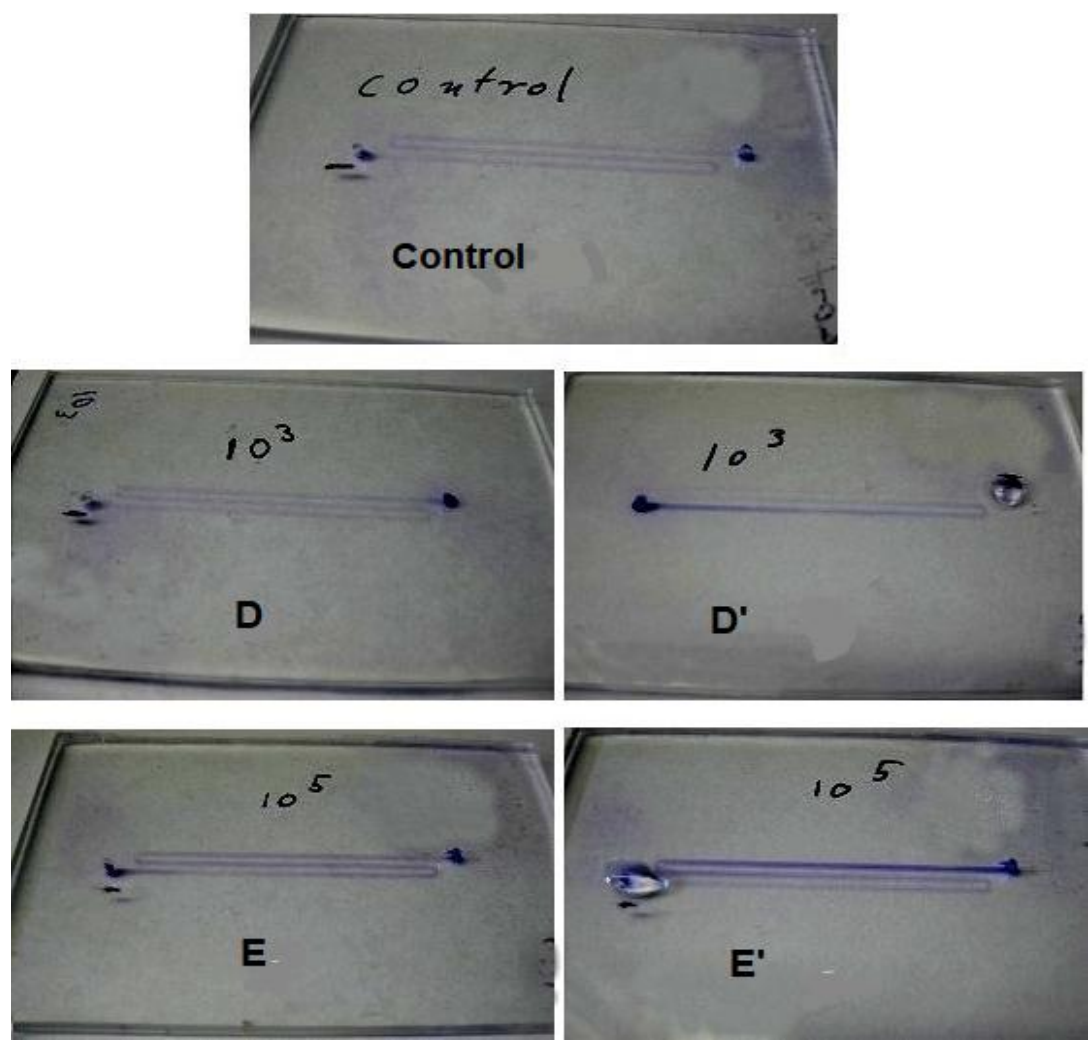

Fig. 5. PDMS microfluidic chip $(5.0 \mu \mathrm{l})$ tested for biofilm formation

Different numbers of bacteria $\left(2.3 \times 10^{3} \mathrm{cells} / \mathrm{ml}\right.$ for D, D', and $2.3 \times 10^{5} \mathrm{cells} / \mathrm{ml}$ for $E$, E') were introduced to the microchannels and incubated at $37^{\circ} \mathrm{C}$ for $12 \mathrm{~h}$. Planktonic media was removed and the PDMS chip was incubated

for $24 \mathrm{~h}$ and then washed three times with sterile saline to remove loosely associated bacteria. Crystal Violet $(1.0 \%$ in water) was introduced as mentioned above and images were taken for stained $(\boldsymbol{D}, \boldsymbol{E})$ and de-stained (D', E') channels using a digital camera

\subsection{Pressure Drop Measurements}

A Bio-Ferrograph provides a constant flow rate by a motor exerting force on a syringe. This leads the fluid through a tube and a pressure transducer into the microchannel. The pressure drop across the PDMS microchannel was measured by a pressure transducer with the difference between the transducer reading and the ambient pressure at the exit of the microchannel. A Bio-Ferrograph can be used together with a pressure transducer to measure the pressure drop across a microchannel. An advantage of using a Bio-Ferrograph for this kind of experiment is that it can provide a constant flow rate between 0.001 and $1 \frac{\mathrm{ml}}{\mathrm{min}}$. A constant volumetric flowrate of $0.1 \mathrm{ml} / \mathrm{min}$ was used in each channel volume size. Since each crosssectional area of the microchannels differ, the velocity of the sterile saline wash in each channel was also different. Hence, using the same constant volumetric flowrate over the varying cross-sectional areas ensured the wash is delivered uniformily. Differences in pressure drop readings were not evident, and hence not affected by the differences in saline velocities, as all the pressure drop readings are on the same order of magnitude. The setup can be seen in (Fig. 3). This set up generated a calibration curve for PDMS microfluidic chips. The three graphs with different designs of microchannels $(2.6,5.0$, and $11.5 \mu \mathrm{l}$ ) show the increase in pressure drop over time (Fig. 8). A constant volumetric flowrate of $0.1 \mathrm{ml} / \mathrm{min}$ was used in each volume channel. Since each cross-sectional area of the microchannels differ, the velocity of the sterile saline wash in each channel was also different. Hence, using the same constant volumetric flowrate over the varying cross-sectional areas ensured the wash is delivered uniformity. Major differences in pressure drop readings were not evident, and hence not affected by the differences in saline velocities, as all the 
pressure drop readings are approximately on the same order of magnitude. Measurements of five microchannels with $5 \mu \mathrm{l}$ volume (Fig. 8, A) and of five microchannels with $11.5 \mu$ volume indicated a stabilization time of approximately ten minutes with the improved design of microfluidic channel (Fig. 8, B), far less than the three hours that were necessary for the first design (2.6 $\mu$ volume) (Fig. 8, C). The stabilization time is an indication of how quickly the resulting constant pressure drop is established. It is a function of the channel dissipative losses such as wall roughness and the fluid-to-channel surface ratio, contributing to the dominating viscous effects prominently illustrated in microchannel flows, as opposed to inertial effects. A shorter stabilization time shows that dissipative effects are lower than in channels with higher stabilization times. While the larger channels $(5 \mu \mathrm{l}$ and $11 \mu \mathrm{l})$ provided a faster stabilization time and enhanced bacterial growth, channels larger than micro size are not more advantageous since higher inertial effects will be present. These effects will not allow for enhanced bacterial growth due to disruption of bacterial adhesion to channel surfaces, which must take place first before accumulated growth of bacteria occurs. Stabilization time was found by plotting the pressure drop measurements and noting the time at which the the pressure drop value became nearly constant.
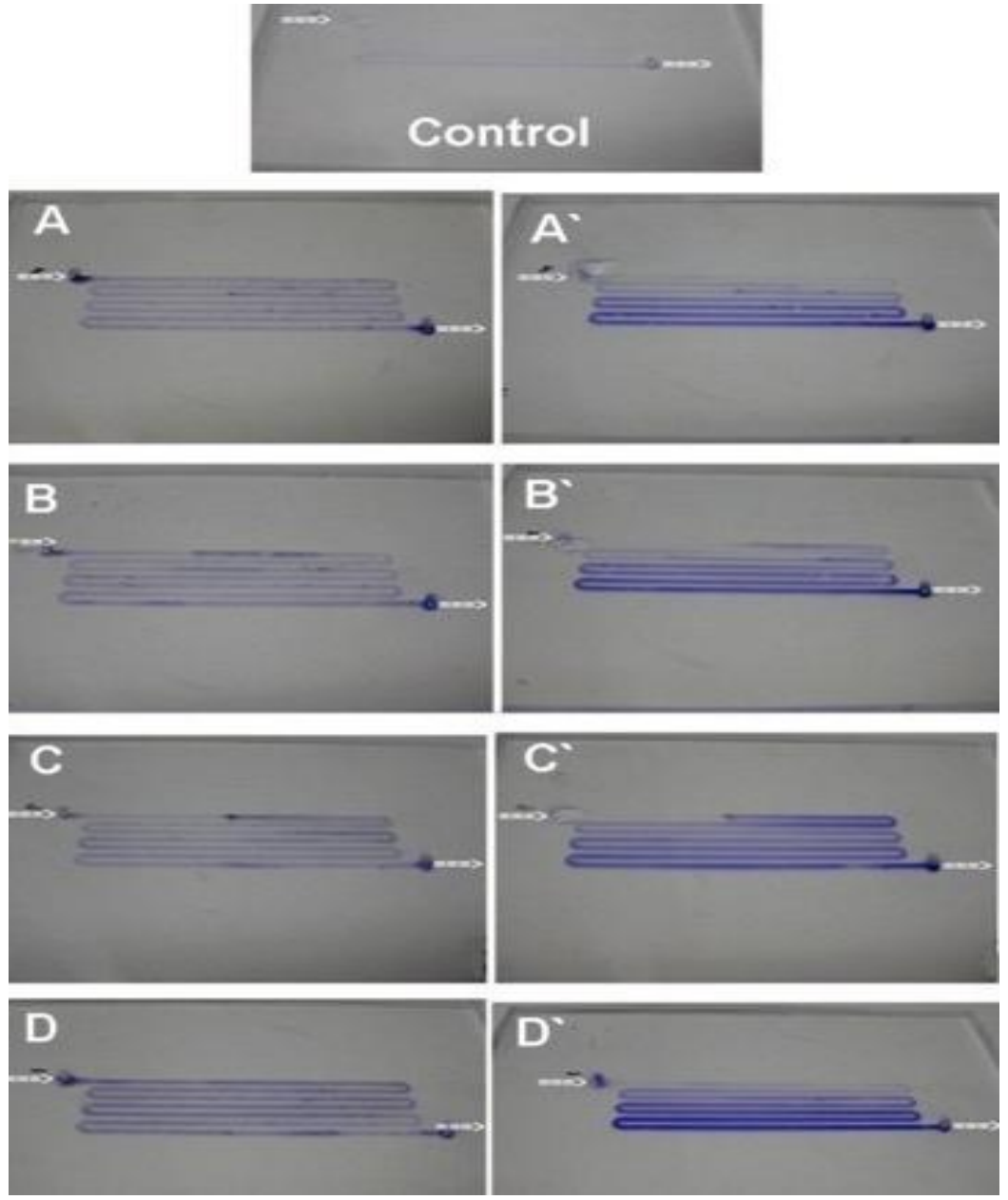

Fig. 6. PDMS microfluidic chip (11.5 $\mu \mathrm{l})$ tested for biofilm formation

Different numbers of bacteria $\left(2.3 \times 10^{3}\right.$ cells $/ \mathrm{ml}$ for $A, A^{\prime}, 2.3 \times 10^{4}$ cells $/ \mathrm{ml}$ for $B, B^{\prime}, 2.3 \times 10^{5}$ cells $/ \mathrm{ml}$ for $C, C^{\prime}$ $2.3 \times 10^{6} \mathrm{cells} / \mathrm{ml}$ for $\left.D, D^{\prime}\right)$ were incubated in microchannels at $37^{\circ} \mathrm{C}$ for $12 \mathrm{~h}$. PDMS chips were prepared as mentioned above. Sterile TSB ${ }^{+}$was used for the control channels. Crystal Violet was introduced as mentioned above and images of stained channels $(A, B, C, D)$ and de-stained channels $\left(A^{\prime}, B^{\prime}, C^{\prime}, D^{\prime}\right)$ were taken using a digital camera 

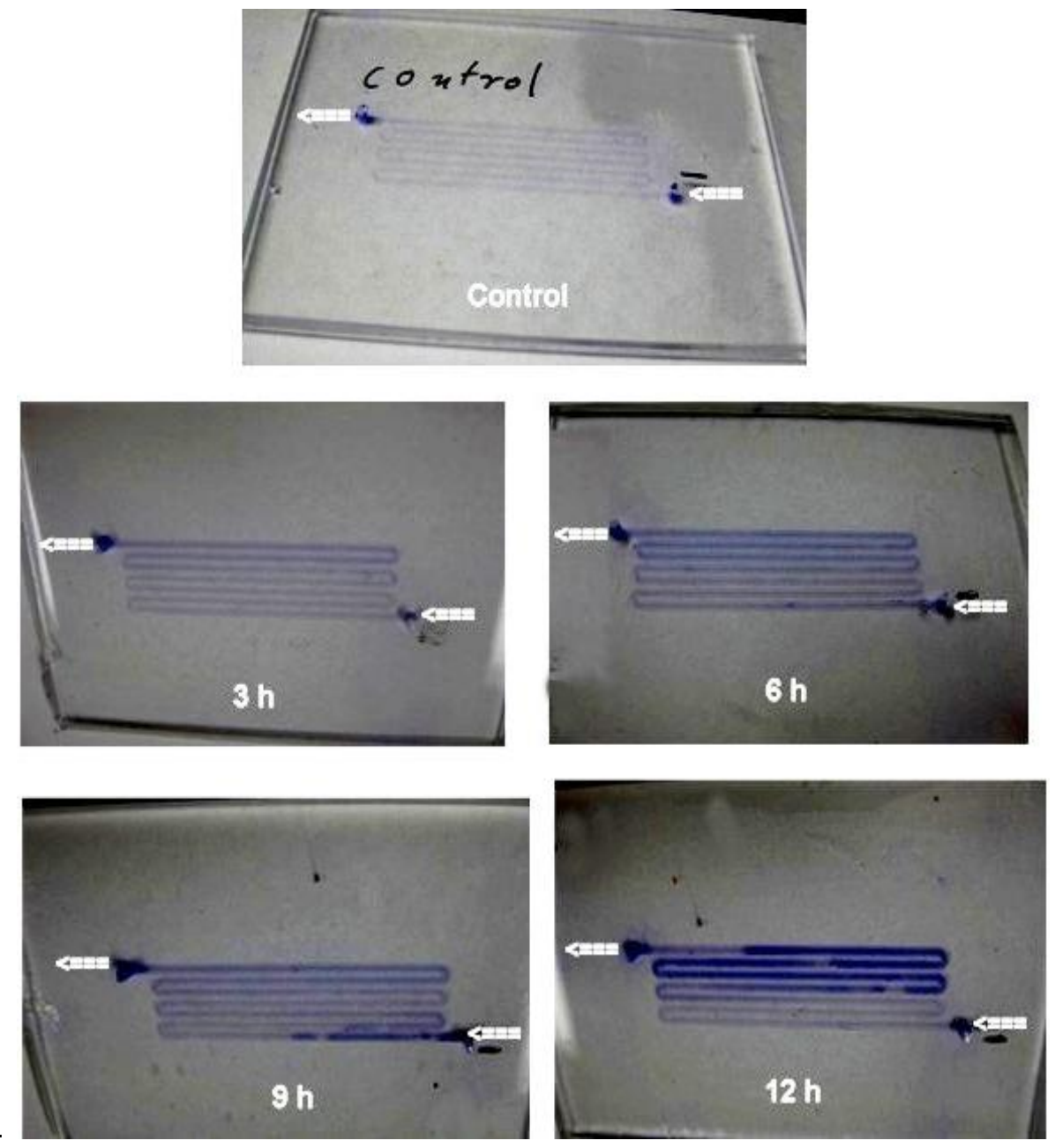

Fig. 7. Effect of incubation time on biofilm formation

A cell suspension of $1 \times 10^{5}$ E. coli $\mathrm{K}_{12}$ in $\mathrm{TSB}^{+}$was delivered to PDMS channels using a syringe tube and incubated at $37^{\circ} \mathrm{C}$ for different time intervals $(0,3,6,9$, and $12 \mathrm{~h})$ in the upper shelf of plastic boxes (Fig. 2). The planktonic cells were removed, incubated at $37^{\circ} \mathrm{C}$ for $12 \mathrm{~h}$ in the upper shelf of plastic boxes, and then washed three times. Controls were conducted by adding sterile TSB ${ }^{+}$. Microchannels were filled with Crystal Violet $(1.0 \%$ in water), incubated at room temperature for $45 \mathrm{~min}$, washed three times with sterile distilled water. Imaging was recorded for de-stained channels using a digital camera

Increases in stabilization time from before incubation to after incubation as noted in Table 1 are a consequence of the increase in volume in the channel of the bacterial growth which, dynamically changing the hydraulic diameter $D_{H}$, which in turn creates a higher hydraulic resistance $R_{\text {hydr }}$ as also seen in Table 1 . Recall from Eq. (1) that very small changes in $D_{H}$, results in higher $R_{\text {hydr }}$, and these higher $R_{\text {hydr }}$ cause the stabilization times to increase.

It is of interest to note that the curves for both 5 $\mu \mathrm{l}$ and $11.5 \mu \mathrm{l}$ microchannels, each representing one microchannel measurement, are relatively similar in their characteristics. The two major improvements of the new design (5.0 and 11.5 $\mu \mathrm{l})$ are the reduction of stabilization time and hydraulic resistance (Table 1 ). A reduction of the stabilization time enhanced bacteria cultivation inside the microchannel due to a larger channel volume and therefore higher oxygen availability. This improved design has a lower hydraulic resistance and also offers more volume for the bacteria cultivation. Advancements in nanotechnology and microfluidics requires microfluidic devices to mimic tiny tubes for studying biofilm formation in biological systems and industrial biotechnology applications. 
Table 1. Stabilization time and hydraulic resistance for the new design Microchannels (11.5.0 $\mu \mathrm{l}$ and $5.0 \mu \mathrm{l})$

\begin{tabular}{|c|c|c|c|c|c|c|}
\hline \multirow{2}{*}{$\begin{array}{l}\text { Volumetric } \\
\text { Flowrate } \\
Q=0.1 \mathrm{ml} / \mathrm{min}\end{array}$} & \multicolumn{3}{|c|}{$11.5 \mu \mathrm{L}$ Microchannels } & \multicolumn{3}{|c|}{$5.0 \mu \mathrm{L}$ Microchannels } \\
\hline & $\begin{array}{l}\text { Theoretical } \\
\text { value }\end{array}$ & $\begin{array}{l}\text { Before } \\
\text { incubation }\end{array}$ & $\begin{array}{l}\text { After } 36 \mathrm{~h} \\
\text { incubation }\end{array}$ & $\begin{array}{l}\text { Theoretical } \\
\text { value }\end{array}$ & $\begin{array}{l}\text { Before } \\
\text { incubation }\end{array}$ & $\begin{array}{l}\text { After } 36 \mathrm{~h} \\
\text { incubation }\end{array}$ \\
\hline $\begin{array}{l}\text { Hydraulic } \\
\text { Resistance, } R_{h} \\
\left(\mathrm{kPa} \cdot \mathrm{s} / \mathrm{mm}^{3}\right)\end{array}$ & 64.7 & 82.3 & 89.01 & 146.2 & 116.9 & 124.1 \\
\hline $\begin{array}{l}\text { Stabilization Time } \\
\text { (sec) }\end{array}$ & - & 600 & 750 & - & 675 & 800 \\
\hline $\begin{array}{l}\text { Average Pressure } \\
\text { Drop, } \Delta p(p s i)\end{array}$ & 15.6 & 8.23 & 8.901 & 35.3 & 11.69 & 12.41 \\
\hline
\end{tabular}
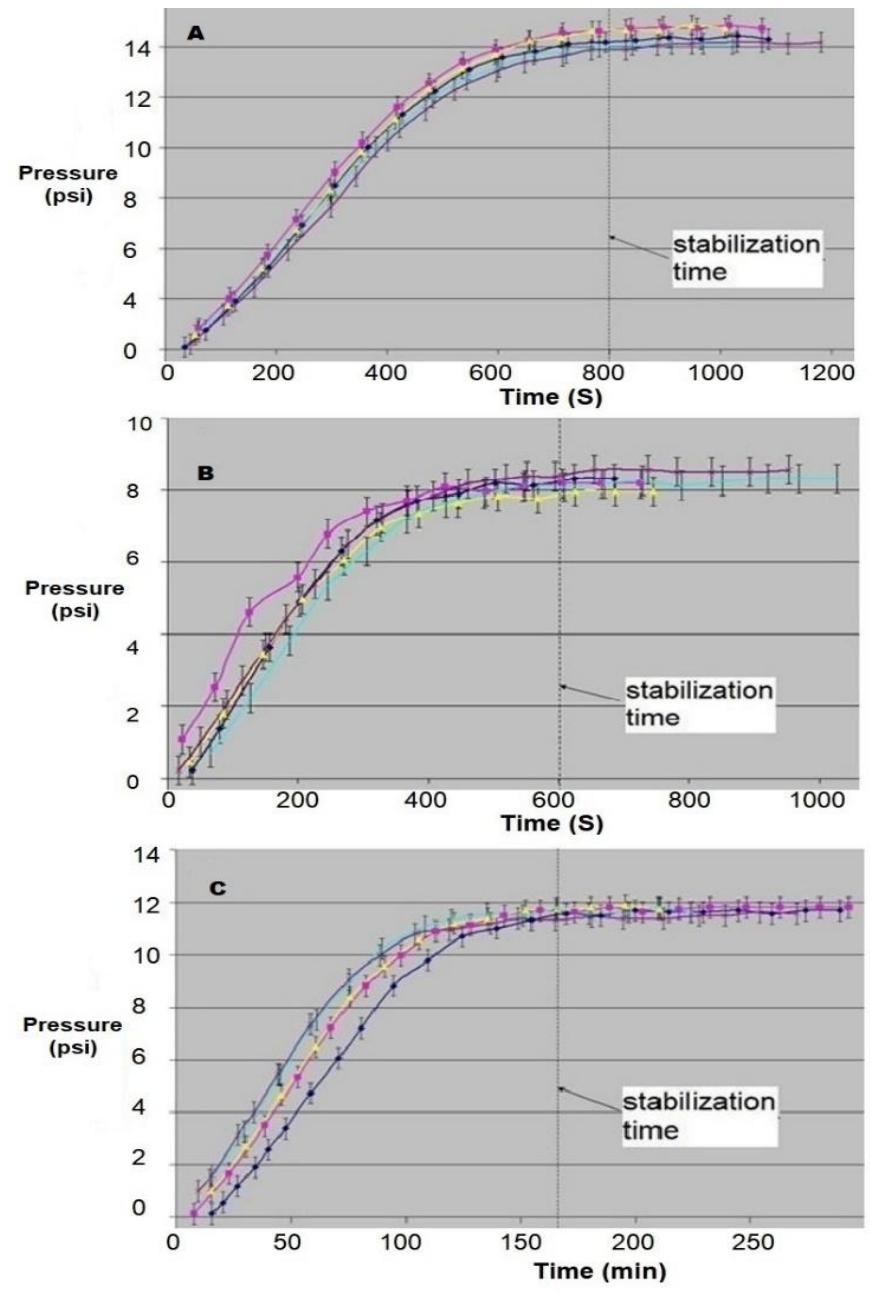

Fig. 8. Pressure drop measurements of microchannels with the new designs. Each curve represents a different microchannel volume, A) $5 \mu \mathrm{l}$, B) $11.5 \mu \mathrm{l}$, and C) $2.6 \mu \mathrm{l}$

Different cell densities of E. coli $\mathrm{K} 12\left(3.55 \times 10^{3}, 3.55 \times 10^{5}, 3.55 \times 10^{6}, 3.55 \times 10^{7}\right.$ cells $\left./ \mathrm{ml}\right)$ were each introduced to PDMS microfluidic chips of each design (A'5.0 $\mu$ l, B' $11.05 \mu l$ and $C^{\prime} 2.6 \mu l$ ), and incubated for $12 h$ as described above. After cell adhesion periods were complete, the planktonic culture media was gently removed and then subjected to another 24 hours for biofilm formation. Sterile saline was then introduced to the channels via the Bio-Ferrograph at a constant flow rate of $0.1 \mathrm{ml} / \mathrm{min}$. Stabilization time and hydraulic resistance were obtained via the Bio-Ferrograph connected to a pressure transducer The experimental data obtained from the pressure transducer was collected by connecting to a computer for generating the graph. Control measurements were taken for each channel before adding bacterial cells 


\section{CONCLUSIONS}

An inexpensive microfluidic PDMS chip was developed for the non-destructive and noninvasive detection of biofilm-forming bacteria. Three different designs of microchannels (2.6, 5.0 , and $11.5 \mu \mathrm{l}$ volumes) were fabricated and tested for adhesion and biofilm formation in a microfluidic system. The highest yield of biofilm formation occurred with microfluidic volume (11.5 $\mu \mathrm{l})$ and detection as low as 26 cells was possible. This microfluidic chip reduced stabilization time, decreased hydraulic resistance and offered large volume for adhesion of bacterial cells and biofilm formation. It allowed bacterial cultivation without any addition of nutrients. Microchannels with high stabilization time $(3 \mathrm{~h})$ did not allow the attachment and cultivation of bacterial cells inside, while $10 \mathrm{~min}$ yielded the highest color intensity of biofilm formation. Cell attachment found to be time-dependent, generating various color intensities of biofilm formation. The microfluidic chip provides a platform to monitor biofilm growth and can be integrated for in situ investigation. This would allow a non-destructive and non-invasive monitoring of the biofilmforming bacteria inside the PDMS microfluidic chip. This work opens the opportunities for further investigations of pressure drop phenomena in microchannels that would go otherswise go unnoticed in macro scale measurements for biological systems, food biotechnology and other industrial biotechnology applications.

\section{ACKNOWLEDGEMENT}

This work was supported by National Science Foundation Partnerships for International Research and Education (NSF-OISE-0530203), University of Rhode Island in Collaboration with Technical University of Braunschweig, Germany.

\section{COMPETING INTERESTS}

Authors have declared that no competing interests exist.

\section{REFERENCES}

1. Costerton JW, Cheng KJ, Geesey GG, Ladd TI, Nickel JC, Das-Gupta M, Marrie TJ. Bacterial biofilms in nature and disease. Annual Review of Microbiology. 1987;41:435-439.

2. Madigan MT, Martinko JM, Dunlap PV, Clark DP. Brock biology of micro- organisms. Pearson Education. 2009;165170.

3. Bendouah Z, Barbeau J, Hamad WA, Desrosiers M. Biofilm formation by Staphylococcus aureus and Pseudomonas aeruginosa is associated with an unfavorable evolution after surgery for chronic sinusitis and nasal polyposis. Otolaryngology Head and Neck Surgery. 2006;134:991-996.

4. Rodriguez AS, McLandsborough LA. Evaluation of the transfer of Listeria monocytogenes from stainless steel and high-density polyethylene to bologna and American cheese. J. Food Prot. 2007;70: 600-606.

5. Pan Y, Breidt F, Kathariou S. Resistance of Listeria monocytogenes biofilms to sanitizing agents in a simulated food processing environment. Appl. Environ. Microbiol. 2006;72:7711-7717.

6. Stopforth JD, Yoon Y, Barmpalia IM, Samelis J, Skandamis PN, Sofos JN. Reduction of Listeria monocytogenes populations during exposure to a simulated gastric fluid following storage of inoculated frankfurters formulated and treated with preservatives. Int. J. Food Microbiol. 2005;99:309-319.

7. Boulange-Peterman L. Processes of bioadhesion on stainless steel surfaces and cleanability: A review with special reference to the food industry. Biofouling. 1996;10:275-300.

8. Pan Y, Breidt F, Kathariou S. Resistance of Listeria monocytogenes biofilms to sanitizing agents in a simulated food processing environment. Appl. Environ. Microbiol. 2006;72:7711-7717.

DOI: $10.1128 / A E M .01065-06$

9. Stopforth JD, Skandamis PN, Ashton LV, Geornaras I, Kendall PA, Belk KE, Scanga JA, Smithm GC, Sofos JN. Impact of inoculum preparation and storage conditions on the response of Escherichia coli 0157:H7 populations to undercooking and simulated exposure to gastric fluid. Appl. Environ. Microbiol. 2006;72:672-679.

10. Samelis J, Sofos JN, Kendall PA, Smith GC. Survival or growth of Escherichia coli O157:H7 in a model system of fresh meat decontamination runoff waste fluids and its resistance to subsequent lactic acid stress. Appl. Environ. Microbiol. 2005;71:62286234.

11. Kumar GC, Anand SK. Significance of microbial biofilms in food industry: A 
review. International Journal of Food Microbiology. 1998;42:9.

12. Characklis W, Cooksey K. Advances in applied microbiology. Academic Press. 1983;94.

13. Noguchi N, Noiri Y, Narimatsu M, Ebisu S. Identification and localization of extraradicular biofilm-forming bacteria associated with refractory endodontic pathogens. Applied and Environmental Microbiology. 2005;71(12):8738-8743.

14. Chmielewski RAN, Frank J. Biofilm formation and control in food processing facilities. Comprehensive Reviews in Food Science and Food Safety. 2003;2:22.

15. Boulange-Peterman L, Barroux B, BellonFontaine MN. The influence of metallic wettability on bacterial adhesion. Journal of Adhesion Science and Technology. 1993;7(3):2.

16. Ramage G, Walle KV, Wickes BL, LopezRibot JL. Standardized method for in vitro antifungal susceptibility testing of Candida albicans biofilms. Antimicrobial Agents and Chemotherapy. 2001;45:2475-2479.

17. Yuehuei A, Friedman RJ. Handbook of bacterial adhesion: Principles, methods, and applications. Humana Press Inc., Totowa. 2000;213-233.

18. Costerton JW, Montanaro L, Arciola RC. Biofilm in implant infections: Its production and regulation. International Journal of Artificial Organs. 2005;28(11):1062-1068.

19. Allison D, Lappin-Scott $\mathrm{PH}$, Wilson $\mathrm{M}$. Community structure and co-operation in biofilms. Society for General Microbiology Symposium. 2000;59:95.

20. Guber AE, Heckele M, Herrmann D, Muslija A, Saile V, Eich-Horn L, Gietzelt T,
Hofmann W, Hauser P, Tanyanyiwa J, Gerlach A, Gottschlich N, Knebel G. Microuidic lab-on-a-chip systems based on polymers fabrication and application. Chemical Engineering Journal. 2004;101: 447.

21. Chabert M, Viovy JL. Microuidic highthroughput encapsulation and hydrodynamic self-sorting of single cells. Proceedings of the National Academy of Sciences. 2008;105(9):3191-3196.

22. Rossier JS, Girault HH. Enzyme linked immunosorbent assay on a microchip with electrochemical detection. Lab on a Chip. 2000;1:153-157.

23. Xia Y, Whitesides GM. Soft lithography. Angewandte Chemie International Edition. 1998;37:550-575.

24. Abolmaaty A, Meyer DML. PDMS chip assay for the detection of biofilm formation. World Appl. Sci. J. 2011;13:1800-1806.

25. Abolmaaty A, Meyer DML. PDMS flow cell for monitoring bacterial adhesion capacity of Escherichia coli 0157:H7 in beverages. Annual Research \& Review in Biology. 2017;15(4):1-12.

26. Okazaki S. Resolution limits of optical lithography. The Journal of Vacuum Science and Technology B. 1991;9(6): 2829-2833.

27. Pratt LA, Kolter R. Genetic analysis of Escherichia coli biofilm formation: Roles of agella, motility, chemotaxis and type I pili. Molecular Microbiology. 1998;30(2):285.

28. Zhang $X$, Coupland $P$, Fletcher PDI, Haswell SJ. Monitoring of liquid flow through microtubes using a micropressure sensor. Chemical Engineering Research and Design. 2009;87:19-24.

(0) 2018 Kolossa et al.; This is an Open Access article distributed under the terms of the Creative Commons Attribution License (http://creativecommons.org/licenses/by/4.0), which permits unrestricted use, distribution, and reproduction in any medium, provided the original work is properly cited.

Peer-review history:

The peer review history for this paper can be accessed here: http://www.sciencedomain.org/review-history/22694 